\title{
Using Systematic Synthetic Phonics to Accelerate Rural Indigenous Children's Acquisition of Early Literacy Skills
}

\author{
Jia Rong Yap \\ University of Malaya, Jalan Universiti, 50603 Kuala Lumpur, Malaysia \\ https://orcid.org/0000-0002-8352-682X \\ Mellisa Lee Lee Chin \\ University of Malaya, Jalan Universiti, 50603 Kuala Lumpur, Malaysia \\ https:// orcid.org/0000-0002-5049-2205
}

\begin{abstract}
Studies focusing on the strategy of phonics in Malaysia have highlighted the insufficiency and ineffectiveness of SBELC phonics training received by teachers, resulting in confusion among them as to what really constitutes effective use of the phonics strategy. On the other hand, systematic synthetic phonics (SSP) has been proven beneficial in accelerating the performance of children in their early literacy. However, few studies have been conducted on English language learners as the majority of those research was focused on native speakers of the English language. Against this background, this article presents a description of a systematic way of teaching phonics that could inform teachers on how the strategy can be optimally utilised to accelerate the performance of students who are possibly at risk of being left behind. It then reports an investigation that compared the efficacy of SSP against SBELC phonics in accelerating the acquisition of early literacy skills with a group of indigenous children residing in the rural parts of Sarawak, Malaysia. Five instruments; (1) productive letter-sound test, (2) free-sound isolation test, (3) reading test, (4) spelling test, and (5) oral-reading fluency test were administered to measure phonemic awareness, decoding, reading, and spelling ability. Data were collected from the pretest and the posttest. The results demonstrate that both groups recorded significant improvement in reading and spelling, but children in the experimental group (SSP) outperformed the control group (SBELC phonics) significantly. Following this, SSP should be implemented in classrooms to help accelerate children's early reading fluency and spelling ability.
\end{abstract}

Keywords: early literacy; English language learners; indigenous children; phonemic awareness; systematic synthetic phonics 


\section{Introduction}

Throughout the course of the reformation of English Language Education (ELE) in Malaysia, various pedagogical approaches have been employed by the Malaysian Ministry of Education (MOE) to ensure the competent acquisition of the language among Malaysians (Hazita, 2016). One significant initiative is the introduction of the Communicative Language Teaching method in the 1982's Primary School Integrated Curriculum (KBSR) to promote second language vocabulary acquisition. This method remains beneficial in the development of communicative competence (Chin, Karunakaran \& Yap, 2019). Presently, the CEFR-aligned Standards-Based English Language Curriculum [CEFR-aligned SBELC] (MOE, 2017) continues to map out "pedagogical approaches [that are] built on the foundations of communicative competences" (pp. 1 - 2). To achieve this, the CEFR-aligned SBELC recommends the principle of going "back to basics" and states that "it is essential for teachers to begin with basic literacy skills in order to build a strong foundation of language skills" (p. 6). Based on this premise, the MOE's move to incorporate phonics as a strategy for English teaching and learning is arguably a step in the right direction in providing a solid foundation for students' subsequent successful acquisition of the English language. Indeed, phonics as a useful strategy for early literacy has been widely acknowledged by both international (e.g., Ehri, 2020; Wyse \& Goswami, 2008) and local researchers (e.g., Su \& Hawkins, 2013; Zulkifli \& Melor, 2019) alike. First introduced in 2011 and as stipulated in the then newly-revamped Standards-Based English Language Curriculum (SBELC), "the Years 1 and 2 learning standards address basic literacy using the strategies of phonics to develop phonemic awareness in pupils to enable them to become independent readers by the end of Year 2" (MOE, 2011, pp. 8-9). This strategy is carried over into the CEFR-aligned SBELC, with two dedicated documents now prepared by the MOE to guide teachers with classroom phonics teaching and learning practices.

However, despite the Malaysian government's substantial investment in revising the English language curriculum and providing continuous professional development courses to teachers, several key challenges remain to be addressed. Fundamentally, the implementation of CEFR-aligned SBELC left much to be desired because teachers lack a full understanding of the suggested teaching methods, and have limited knowledge of the curriculum altogether due to the inadequacy of training (Sidhu, Kaur \& Chi, 2018). Next, studies focusing on the strategy of phonics in Malaysia (e.g., Nadiah Yan, Napisah \& Mariyatunnitha, 2014; Rabindra, Nooreiny \& Hamidah, 2016) have similarly highlighted the inconsistency, insufficiency, and ineffectiveness of the SBELC phonics training received by teachers, resulting in misconceptions and confusion among teachers as to what really constitutes effective use of the phonics strategy.

In this regard, systematic synthetic phonics (SSP) could be the answer to the abovementioned issues. Educational groups in Anglophone countries such as the United States of America's National Institute of Child Health and Development, the United Kingdom's Department for Education and Skills (through recommendations of The Rose Review, 2006), New Zealand Ministry of Education's Literacy Experts Group, and Australian National Inquiry into the 
Teaching of Literacy have acknowledged the centrality of SSP in accelerating the acquisition of early literacy (Bowey, 2011; Jolliffe, Waugh \& Gill, 2019). As suggested in the term itself, the superiority of SSP lies in its systematicity. It begins with developing learners' phonemic awareness through the letter-sound training (both productive and receptive), followed by the five-phase phonics training, and the after-phase blending and segmenting practices. Additionally, SSP includes pseudowords to ensure children apply the phonics strategy in reading and spelling. In comparison, the SBELC phonics conducts the letter-sound training and phonics training concurrently. It uses only real words, with occasional blending and segmenting activities. Unsurprisingly, findings from the present study have shown the experimental group (SSP) outperforming the control group (SBLEC phonics) in their early literacy skills.

Against this background, the purpose of this article is two-fold. First, it advocates for and presents a detailed description of a systematic way of teaching phonics that could inform teachers on how the strategy can be optimally utilised to accelerate the performance of students who may be at risk of being left behind (or are still preliterate at Primary 1/Primary 2). Second, as a means of supporting the effectiveness of SSP, it reports an investigation that compared the SSP programme with SBELC phonics in imparting early literacy skills among young learners in the rural setting. In the study, early literacy was defined as reading fluency and writing in the form of spelling ability, whereby children's performances were measurable for documentation purposes (Purewal, 2008).

\section{Literature Review}

\subsection{Phonics for Early Literacy}

Fundamentally, phonics is a goal of enabling learners to associate sounds to the prints and subsequently to transfer this skill into reading or spelling. It is also an umbrella term that constitutes an organised set of rules about vowels, consonantblends and syllables, the key to which is to recover the sounds from the prints (Griffith \& Olson, 1992). It reflects Rose's (2006) Simple View of Reading that posits reading as a two-process skill; (i) the automatic word recognition skills, and (ii) the ability to tap into prior knowledge and experience to gain comprehension. The fundamental step in achieving word recognition is decoding, whereby a child can associate the sounds (phonemes) represented by a letter or a combination of letters (graphemes), and to identify the complete word (Rose, 2006). Rose (2006) further emphasises that decoding is the precursor to comprehension and as such, children need to first acquire the decoding skills in their beginning reading before they are to progress to the task of comprehension.

Having said that, for successful teaching of reading and spelling through phonics, the development of learners' foundation in phonemic awareness should take precedence. According to Cunningham (1988, as cited in Griffith \& Olson, 1992), phonemic awareness is the understanding that the sounds of a spoken language work together to make words. Specifically, phonemic awareness does not sound out words, but its skill enables children to use grapheme-phoneme relationships to read and spell words by understanding the structure of the spoken language. Ukrainetz et al. (2000) propose that this can be achieved by carefully choosing the 
type of phonics instructions, defined as teaching practices that are designed to help students acquire knowledge of the relationships between graphemes and phonemes, and the ability to do blending (Armbruster, Lehr \& Osborn, 2001). An essential component of phonics, blending is the process of putting individual phonemes together to read a complete word and it requires phonemic awareness (Griffith \& Olson, 1992). Beck and Beck (2013) further recommend scaffolding blending whereby this sequential process of learners sounding each phoneme, remembering the sequence, and blending the segments be developed. This scaffolding blending process was integrated into this study as part of the systematic synthetic phonics programme, which is discussed in further detail in the subsequent section.

\subsection{Systematic Synthetic Phonics}

The term 'Systematic Synthetic Phonics' engaged in this study is composed of two major concepts; (i) systematic phonics instruction, and (ii) synthetic phonics. Exactly a score years ago, the US National Reading Panel (2000) released a 449page report which reviewed more than 100000 research studies on reading and has recommended systematic phonics instruction for reading. Correspondingly, Mesmer and Griffith (2005) explain that a systematic phonics programme encompasses three elements; (i) a curriculum with a specific, sequential set of phonics elements, (ii) instruction that is direct, precise and unambiguous, and (iii) opportunities for learners to use phonics to read words. As for synthetic phonics, this approach begins by teaching learners the identification of phonemes that are represented by graphemes in a word, before putting them together to form a complete word (de Graaff, Bosman, Hasselman \& Verhoeven, 2009). It shares the principles in the bottom-up processing of reading which views the ability to decode efficiently and to recognise words automatically as vital skills. De Graaff et al. (2009) suggest that once learners grasped these basic grapheme-phonemes correspondences (GPCs), they can decode a number of words in English without much difficulty and hence expand their reading vocabulary.

\subsection{Systematic Synthetic Phonics Programme}

The Systematic Synthetic Phonics (SSP) programme in this study embraces all the elements of systematic phonics presented by Mesmer and Griffith (2005) and is inspired by de Graaff et al.'s (2009) computer-assisted model which has been modified into a human model. This SSP programme contains two parts. Firstly, the letter-sound training introduces the phonemes and their represented graphemes and is organised into two sections: (i) the receptive and (ii) the productive. In the receptive way of training, the teacher says aloud a phoneme twice and then places four graphemes cards ( 1 target phoneme, 3 distractors) before their learners. The learners listen to the phoneme uttered and select its corresponding grapheme out of the four cards. In the productive way of training, the learners see the grapheme cards first and point at the corresponding graphemes as the teacher produces the phonemes orally. Once the learners have undergone the letter-sound training and successfully mastered all the phonemes and their corresponding graphemes, they advance into the phonics training.

In this part of the programme (phonics training), learners are required to practise reading, blending, and segmenting randomly presented words and pseudowords. 
Pseudowords are a pronounceable combination of graphemes that have the characteristics of a known real word but are not real words according to common English dictionaries (Cardenas, 2009, in de Graff et al., 2009). For instance, the phoneme ai/eI/ may form words such as 'sail' and 'bail', or pseudowords like 'dail' and 'phail'. Their integration is unique to this SSP programme, as using both words and pseudowords will ensure learners acquire the intended phonics knowledge for reading, and the syllabic patterns for spelling (Harris \& Hodges, 1995). This phonics training is planned to be carried out in stages, with a predetermined number of target GPCs in each stage. Nevertheless, despite the emphasis on adhering to the scope and sequence of introducing the GPCs, the teacher holds the autonomy in deciding the number of GPCs to begin with in the first stage, and the addition of new GPCs in the subsequent stages until all 44 phonemes are covered. The decision can be made depending on their learners' capability and progress.

Another important feature of this SSP programme is that each stage comprises five phases. In Phase 1, the graphemes at the beginning and the end of the word/pseudoword [(pseudo)word] are given. In Phase 2, only the grapheme at the end is given. In Phase 3, the grapheme at the beginning is given. In Phase 4, no graphemes are given and in Phase 5, a complete CVC (pseudo)word is given. Specifically, in Phase 5, learners have to select the corresponding (pseudo)word spoken by the teacher out of the four presented word-cards ( 1 target word, 3 distractors). The construction of 15 words in the first four phases and the synthesising of 10 words in Phase 5 entitle the learners to proceed to an extended blending and segmenting practice. In this after-phase activity, the teacher will demonstrate smooth blending (the sounding of phonemes without pausing) and smooth segmenting (the automatic association of a phoneme to its grapheme) as a part of the skills training. For the next two sessions, learners practise blending to form complete (pseudo)words and segmenting them for spelling. When all the five phases within a stage are completed and the learners are able to blend and segment 10 (pseudo)words, they progress to the next stage. A summary of the phases and an overview of the SSP programme are presented in Table 1 and Figure 1, respectively.

Table 1: Summarised details of phases in a stage in SSP

\begin{tabular}{|c|c|c|c|}
\hline Phase & $\begin{array}{l}\text { Sample Item } \\
\text { (CVC word) }\end{array}$ & Description & Example \\
\hline 1 & & $\begin{array}{c}\text { Graphemes at the beginning and the } \\
\text { end are given }\end{array}$ & $\mathrm{m} \_\mathrm{d}$ \\
\hline 2 & $\begin{array}{l}\text { maid jail train } \\
\text { snail float foam } \\
\text { goat toast ties }\end{array}$ & Grapheme at the end is given & $\begin{array}{l}-{ }^{\mathrm{d}} \\
-{ }^{\mathrm{m}}\end{array}$ \\
\hline 3 & $\begin{array}{l}\text { lies pies dies } \\
\text { sheep green cheek }\end{array}$ & Grapheme at the beginning is given & $\frac{\mathrm{m}}{\mathrm{f}--}$ \\
\hline 4 & wheel torch sport & No graphemes are given/presented & --- \\
\hline 5 & $\begin{array}{l}\text { fork form } \\
\text { *words in italic are } \\
\text { used as examples }\end{array}$ & $\begin{array}{l}\text { A complete CVC (pseudo)word is } \\
\text { given. Learners select the } \\
\text { corresponding (pseudo)word spoken } \\
\text { by the teacher out of the } 4 \text { wordcards } \\
\text { given ( } 1 \text { target word, } 3 \text { distractors) }\end{array}$ & $\begin{array}{l}\overline{\text { 1. maid }} \overline{\text { m.* }} \\
\text { 2. foam } \\
\text { 3. form } \\
\text { 4. green } \\
* \text { target word }\end{array}$ \\
\hline
\end{tabular}


Systematic Synthetic Phonics (SSP) Programme

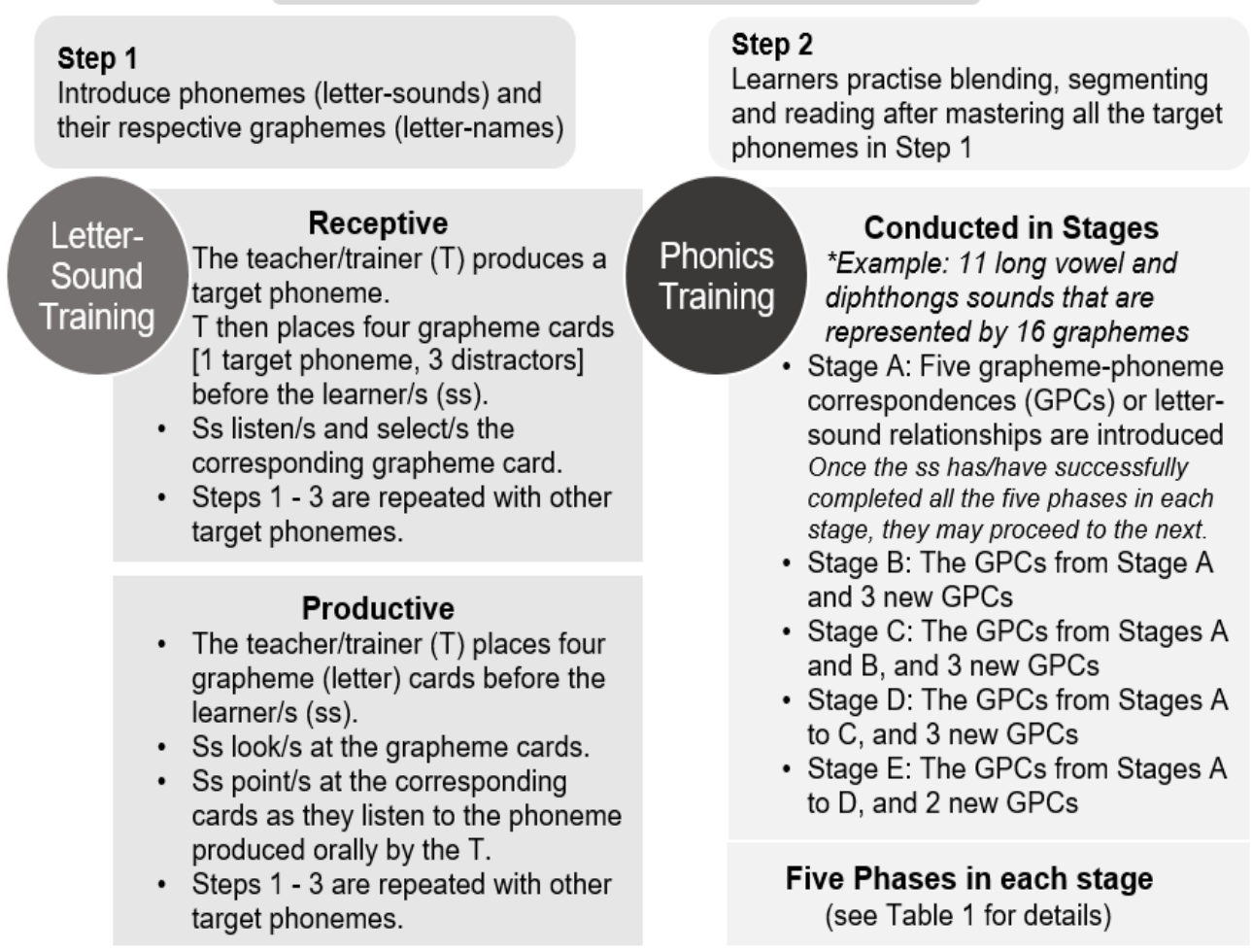

Figure 1. An overview of the Systematic Synthetic Phonics programme

To date, despite the growing body of literature that supports the benefits of systematic synthetic phonics, little studies have been conducted on children who are English language learners as the majority of those research was focused on native speakers of the English language (McGeown, Johnston \& Medford, 2012; Watts \& Gardner, 2012; Wyse \& Goswami, 2008; Yap, 2014). Therefore, as outlined in the purpose of this article, the next section presents a quantitative randomised comparison experimental study that investigated the effects of SSP and SBELC phonics on reading fluency and spelling ability with a group of indigenous children (Iban) residing in the rural parts of Sarawak. These children were likely to be at a higher risk of falling behind their city peers in early literacy if their ability to read in the English language was not addressed in time (UNICEF, 2008). The hypothesis and research questions are as follows:

The indigenous children who undergo SSP training will attain higher levels of reading fluency and spelling ability than the children who receive SBELC phonics training.

1. What is the relative effect of SSP as compared to the SBELC phonics on children's early reading fluency?

2. What is the relative effect of SSP as compared to the SBELC phonics on children's early spelling ability?

\section{Method}

The experimental study, which was quantitative in nature, took place in a real-life natural setting of an educational organisation. It intended to prove the hypothesis by determining whether or not the independent variable (the type of phonics 
training) caused an effect on the dependent variable (the children's reading fluency and spelling ability). It followed the features of a true experimental study with the inclusion of three key components - (i) pre-posttest design, (ii) a treatment (or experimental) group and a control group, and (iii) random assignment of study participants (Carpenter et al., 1989).

\subsection{Participants}

The participants in the present study consisted of 32 Primary 2 schoolchildren, in which they were equally and randomly assigned into either the experimental or the control group. They were from three neighbouring national schools located in the rural parts of Bintulu, Sarawak. This study had engaged a non-probability sampling method in the recruitment of participants, as they were the researchers' existing students and students of English teachers known to the researchers. Table 2 shows the participants' mean age, socioeconomic status, and level of proficiency from the SBELC school-based assessment.

Table 2: Participants' background

\begin{tabular}{lccc}
\hline Mean age & \multicolumn{3}{c}{92.6 months (SD $=3.5$ months) } \\
\hline Socioeconomic status & Good & Average & Hardcore Poor \\
& 15 & 8 & 9 \\
\hline Level of proficiency & Band 3 & Band 2 & Band 1 \\
from SBELC assessment & 7 & 20 & 5 \\
\hline
\end{tabular}

The children were a homogenous group from the indigenous tribe of 'Iban or Sea Dayak'. Before primary education, all 32 participants had received a year of kindergarten education and mastered all the 26 letter-names in the English alphabet. However, formal learning and immersion into English language only began in Primary 1. As SBELC phonics began in Primary 1, they had learned and mastered 30 GPCs of 21 consonants, five short vowels, and four digraphs. This conclusion was made based on the results of the achievement test where all 32 of them received perfect scores, conducted at the beginning of 2013. The objectives and nature of the experiment were explained to the participants' parents prior to obtaining their consent. They also met the following inclusion criteria: (a) indigenous children from the rural parts in Sarawak, (b) learning English as a foreign language, (c) undergoing SBELC phonics for reading, and (d), the ability to attend phonics training for 30 minutes a day.

\subsection{Phonics Training Procedure}

The experiment consisted of two types of training: the SSP and the SBELC phonics. Both phonics-training programmes contained 40 sessions of 30-minute each that were executed over a period of eight weeks. The training duration and session were planned in conformity with the SBELC phonics scheme-of-work. The participants had 60 minutes of English lesson daily from Mondays to Fridays and learnt approximately nine GPCs in eight weeks. The researcher purchased commercially available Jolly Phonics products from the authorised distributor in Malaysia and conducted the SSP training with the experimental group. This study recruited the help of one phonics-instruction trained teacher to act as the SBELC phonics trainer and also as the inter-rater (Teacher $\mathrm{X}$ ). Teacher $\mathrm{X}$ carried out 
SBELC Phonics training with the control group using the materials in the form of textbook and teachers' guidebook provided by the MOE. Prior to the actual experimentation, the researcher and Teacher $X$ (the trainers) simulated the training procedures in SSP and SBELC Phonics twice to ensure a uniform administration of the phonics training.

\subsection{Training Scope and Sequence}

Scope refers to the content of the phonics instruction and the range of GPCs covered, while sequence is the order for teaching the GPCs. Both the experimental and control groups were given the same 11 long vowel and diphthong sounds (phonemes) represented by 16 graphemes. Thus, both groups have 16 GPCs (ai/er/, oa/əv/, ie/ar/, ee/i:/, or/o:/, oo/v/, oo/u:/, oi/or/, ou/av/, er/ə:/, ar/a:/, ay/er/, ow/ov/, igh/ar/, ea/i:/, and ue/u:/). The IPA symbols were not introduced to the participants to avoid possible confusion.

\subsubsection{Systematic Synthetic Phonics (SSP) Training}

Following the procedure as presented in Figure 1, the SSP training began with the letter-sound training in which one GPC was taught in each session and altogether 16 sessions were allocated for this. The phonics training comprised 24 sessions and required the participants to practise reading, blending, and segmenting randomly presented (pseudo)words in five stages. At Stage A, children practised with randomly presented (pseudo)words with the five GPCs of ai/eI/, oa/ov/, ie/aI/, ee/i:/, and or/o:/. Each participant was given two attempts to listen to the (pseudo)words given by the researcher and fill in the blanks with the grapheme-cards provided to form the complete CVC (pseudo)words. Upon the second erroneous attempt, the correct answer was given. Participants jotted down the correctly formed words into their personal logbooks as a record of their individual progress. This allowed them to proceed at an individual pace. The participants went through the five phases in each stage (see Table 1). Three new GPCs were added in Stage B (oo/v/, oo/u:/, oi/or/), Stage C (ou/av/, er/ə:/, ar/a:/), Stage D (ay/ei/, ow/ov/, igh/ar/) and lastly, two in Stage E (ea/i:/, $\mathrm{ue} / \mathrm{u}: /)$. When all the five stages have been completed, children repeated the five phases in Stage E until all 24 sessions were fulfilled.

\subsubsection{SBELC Phonics Training}

The letter-sound training and phonics training ran concurrently in SBELC phonics training. Teacher $\mathrm{X}$ extracted the phonics components, the accompanying word list and reading texts from the SBELC Year 2 English textbook and followed the phonics instructions and activities stipulated in it. The SBELC phonics training procedure was repetitive in nature, beginning with the introduction to and practices of sounding out the target phonemes. The children were to associate a phoneme to its corresponding grapheme by choosing the correct letter card. Then, they were instructed to listen to a list of words presented to them by Teacher $X$ and to orally identify the vowel sound in those words. For example, the vowel sound in 'broach' is oa/ov/. After that, they were expected to know how to blend and segment by using the list of words provided in the textbook. The phonics training of every unit ended with a reading text. The text integrated some of the target GPCs and encompassed CVC, CV and VC words. The reading texts also contained two- and three-syllable words that required Teacher $\mathrm{X}$ to demonstrate 
using the whole-word approach. In each unit, two new phonemes were introduced, with no reference or revision of the past phoneme learnt.

\subsection{Instruments}

The trainers attended two training sessions a fortnight before the pretest in April to ensure a uniform administration of the tests. The tests took place in the evening at the school's library, after the day's schooling session has concluded. The whole process was digitally recorded for all five tests, to allow for an after-test review and cross-examination between the trainers. Also, the Malaysian English curriculum uses Standard British English as a reference and model for teaching the language, as well as for spelling and pronunciation for standardisation (MOE, 2011). As such, the judgment of the pronunciation of phonemes cross-referred to the phonemic chart from the British Council website. The judgment of the pronunciation of words was cross-referred with oxforddictionaries.com. Nonetheless, following studies by Wang and Koda (2005), all acceptable pronunciations were scored correct. For example, the word 'sail' pronounced as /seil/ and /scl/ were both acceptable.

Pretest and Posttest. The participants were tested twice; before the experiment commenced in May (pretest) and after the experiment in August (posttest). Five tests measuring (a) productive letter-sound knowledge, (b) phonemic awareness, (c) reading ability, (d) segmenting/spelling ability, and (e) sentence-level reading ability were administered to each child individually for a maximum of 30 minutes each. Tests (a) to (d) and their scoring criteria were adapted from de Graaff et al. (2009). Test (e) and its scoring criteria were adapted from Eun (2012). The adaptations were necessary as the content needed to correspond to the phonemes introduced in this study. Each of the instruments is elaborated below.

Productive Letter-Sound Test (PLST). This test measured the participants' knowledge of the GPCs. They were given letter cards containing the sixteen GPCs presented during the letter-sound training and asked to produce the phonemes. The trainers gave a short demonstration (using the GPCs ur/3:/, ng/n/) and the children practised with two non-tested GPCs $(\mathrm{a} / \mathfrak{x} / \mathrm{ch} / \mathrm{g} /)$ before the actual testing commenced. This test carried a minimum score of 0 and a maximum score of 16 , with 1 point being given for each successful sound-production.

Free Sound-Isolation Test (FSIT). This test was conducted to test the participants' phonemic awareness. They were presented with a list of 12 consonant-vowel (CV) and 36 consonant-vowel-consonant (CVC) words (see Table 3 ). These words were selected from the SBELC Year 2 English textbook, and they included the vowel sounds presented in the experiment. The children were asked to segment the words on the word chart into their individual sounds or to identify the phonemes present in a word. For example, the word 'pail' has three phonemes /p/ei/l/. Those children who have achieved phonemic awareness would be able to identify and say $/ \mathrm{p} /$, / eI/ and $/ 1 /$. The trainers gave a short demonstration and children practised orally with two non-tested words before the actual test began. This test carried a minimum score of 0 and a maximum score of 132, with 1 point being awarded for each successful sound- production. 
Table 3: Free Sound-Isolation Test

\begin{tabular}{|c|c|c|c|}
\hline \multicolumn{4}{|c|}{$\begin{array}{l}\text { Demonstrated word: pail } \\
\text { Practiced words: coat, fork }\end{array}$} \\
\hline \multicolumn{2}{|c|}{ CV words } & \multicolumn{2}{|c|}{ CVC words } \\
\hline bow & loud & float & stern \\
\hline lie & farm & sheep & cart \\
\hline flow & maid & hook & light \\
\hline tray & dream & boil & jail \\
\hline die & train & herd & foam \\
\hline day & mouth & room & cheek \\
\hline grow & form & night & shook \\
\hline true & moon & cream & coin \\
\hline glue & cloud & boat & nerd \\
\hline pie & sharp & green & sport \\
\hline play & torch & look & fight \\
\hline sue & peak & join & stool \\
\hline
\end{tabular}

Reading Test (RT). A total of $3 \mathrm{CV}, 13 \mathrm{CVC}$ words, and $3 \mathrm{CV}, 13 \mathrm{CVC}$ pseudowords were administered to gauge the children's blending skills (see Table 4). The final list was derived from a combination of (pseudo)words formed from the 21 consonants, 14 digraphs acquired in Primary 1, and the 16 vowel sounds presented during the training. The items were both in accordance with the 5 stages of SSP training and SBELC Phonics training. To elaborate, the vowel sounds from Stage A formed 10 items, Stages B to D formed six items each and lastly, Stage E formed four items. The children were presented with the list of 32 (pseudo)words and were required to read each (pseudo)word aloud. In the event of a child mispronouncing a word, they were instructed to engage their blending skills. However, if they still could not read the word after two additional tries, they would proceed to the next word. This test carried a minimum score of 0 and a maximum score of 32, with 1 point awarded for each successful (pseudo)word produced.

Table 4: Summary of words formed from stages A - E

\begin{tabular}{|c|c|c|c|c|}
\hline Stage & Phoneme & Word & Pseudoword & Number of Item \\
\hline \multirow[t]{5}{*}{ A } & ai /eI/ & said & bain & 10 \\
\hline & oa / əo / & gloat & coam & \\
\hline & ie /aI/ & lie & wie & \\
\hline & ee /i:/ & steep & cheel & \\
\hline & or $/ \mathrm{o:} /$ & stork & chorm & \\
\hline \multirow[t]{3}{*}{ B } & $00 / v /$ & crook & pook & 6 \\
\hline & oo / u/ & droop & flop & \\
\hline & oi / ग1/ & coil & moin & \\
\hline \multirow[t]{3}{*}{ C } & ou /av/ & stout & boust & 6 \\
\hline & er /ə:/ & perch & wern & \\
\hline & ar /a:/ & chart & spart & \\
\hline \multirow[t]{3}{*}{$\mathrm{D}$} & ay/ei/ & dray & glay & 6 \\
\hline & ow / / & grow & drow & \\
\hline & igh /aI/ & flight & spight & \\
\hline E & ea /i:/ & speak & pleak & 4 \\
\hline
\end{tabular}


Segmenting Skill/Spelling Test (ST). The 32 items presented during the reading test were reemployed to determine children's spelling ability. The children were asked to write the sounds they heard in a (pseudo)word, in sequential order. This test carried a maximum score of 32, with 1 point awarded for each (pseudo)word spelt correctly.

Oral-Reading Fluency Test (ORFT). This test was administered to determine the participants' reading fluency, defined as the ability to read a piece of text automatically and accurately with expressions. However, prosody was not included in the test as studies by Jiang, Sawaki and Sabatini (2012) and Lems (2003, in Eun, 2012) have reported on the difficulty to achieve an acceptable reliability given the subjective nature of deciding desirable prosody. The text was adopted from Jolly Readers Level 2, published by Jolly Learning Limited. It featured words that were phonetically decodable, and could be sounded out with the 21 consonants, 14 digraphs acquired in Primary 1, and the 16 vowel sounds presented during training in the current study. However, unlike the Reading Test (RT), ORFT assessed participants' ability to read at the sentence level by counting the number of words the children read in a minute.

ORFT was conducted in this manner. The trainers and the children each had a copy of the same reading text. The children were instructed to begin reading aloud and while they read, the trainers noted any errors the children made by circling the mispronounced words in their copy. Once the minute on the stopwatch held by trainers was up, they marked in their sheet the children's progress at the $60^{\text {th }}$ second and let them finish reading the text. The trainers then totalled the number of words read within 60 seconds and subtracted them with errors made by the children. For the purpose of this study, only errors made on the trained vowel sounds were considered. For example, if 'Child $\mathrm{A}^{\prime}$ read 65 words in a minute but made a total of 6 errors ( 2 untrained-vowel words, 4 trained-vowel words), their reading rate would be 61 words correct per minute. The children's oral reading fluency rate was compared against the benchmark adapted from Johns and Berglund (2009), which states that the average second grade or primary 2 students' mean words targets is 50 correct words per minute in February, 70 in June, and 90 in October.

\subsection{Data Analysis}

Data for this study were analysed using IBM Statistical Packages for Social Sciences (SPSS) version 21. The findings are presented in two parts. The first part consists of the analysis of the pretest for both the experimental (SSP) and control groups (SBELC Phonics) using independent samples t-test. This was conducted in order to establish equality among both groups' early literacy levels before the intervention. Levene's test for equality of variance was applied. Next, the hypothesis and research questions were addressed through the analyses of paired-samples t-test for each outcome variable. A paired-samples t-test was used to compare the means of the pretest and posttest scores obtained from the experimental group and control group, in order to determine the effectiveness of the phonics training by looking at the significant difference between the two scores. 


\section{Findings and Discussion}

\subsection{Analyses of Pretest}

The results of the pretest aimed at establishing the assumption of equality of variance are presented in Tables 5 and 6 . The null hypothesis to be tested (Ho: $\mu \mathrm{E}$ $=\mu \mathrm{C})$ states that the PLST, FSIT, RT, ST and ORFT pretest mean scores of the experimental group are equal to the pretest mean scores of the control group. Conversely, the alternative hypothesis $(\mathrm{H} 1: \mu \mathrm{E} \neq \mu \mathrm{C})$ states that the pretests PLST, FSIT, RT, ST and ORFT mean scores of the experimental group are not equal to the pretests mean scores of the control group. The significance level alpha is specified at 05 .

Table 5: Descriptive statistics

\begin{tabular}{cccrcr}
\hline & Groups & N & Mean & Std. Deviation & $\begin{array}{r}\text { Std. Error } \\
\text { Mean }\end{array}$ \\
\hline PLST & Experimental & 16 & 5.688 & 1.195 & 0.299 \\
& Control & 16 & 5.750 & 1.390 & 0.348 \\
FSIT & Experimental & 16 & 96.625 & 7.013 & 1.753 \\
& Control & 16 & 96.938 & 6.547 & 1.637 \\
RT & Experimental & 16 & 10.375 & 2.446 & 0.612 \\
& Control & 16 & 10.750 & 2.206 & 0.552 \\
ST & Experimental & 16 & 7.500 & 2.129 & 0.532 \\
& Control & 16 & 8.125 & 2.306 & 0.576 \\
ORFT & Experimental & 16 & 34.500 & 5.808 & 1.452 \\
& Control & 16 & 34.438 & 6.491 & 1.623 \\
\hline
\end{tabular}

Table 6: Independent samples t-test

\begin{tabular}{|c|c|c|c|c|c|c|c|c|c|}
\hline \multirow[t]{3}{*}{. } & \multicolumn{2}{|c|}{$\begin{array}{c}\text { Levene's } \\
\text { Test for } \\
\text { Equality of } \\
\text { Variances }\end{array}$} & \multicolumn{5}{|c|}{ t-test for Equality of Means } & & \\
\hline & \multirow[t]{2}{*}{$\mathrm{F}$} & \multirow[t]{2}{*}{ Sig. } & \multirow[t]{2}{*}{$t$} & \multirow[t]{2}{*}{$\mathrm{df}$} & \multirow{2}{*}{$\begin{array}{l}\text { Sig. (2- } \\
\text { tailed) }\end{array}$} & \multirow{2}{*}{$\begin{array}{r}\text { Mean } \\
\text { Diff. }\end{array}$} & \multirow{2}{*}{$\begin{array}{l}\text { Std. Error } \\
\text { Diff. }\end{array}$} & \multicolumn{2}{|c|}{$\begin{array}{l}95 \% \text { CI of } \\
\text { Difference }\end{array}$} \\
\hline & & & & & & & & Lower & Upper \\
\hline PLST & .104 & .750 & -.136 & 30 & .892 & -.063 & .458 & $\begin{array}{l}.999 \\
\end{array}$ & .874 \\
\hline FSIT & .062 & .805 & -.130 & 30 & .897 & -.313 & 2.399 & -5.211 & 4.586 \\
\hline RT & .239 & .628 & -.455 & 30 & .652 & -.375 & .823 & -2.057 & 1.307 \\
\hline ST & .085 & .772 & -.797 & 30 & .432 & -.625 & .785 & -2.227 & .977 \\
\hline ORFT & .092 & .763 & .029 & 30 & .977 & .063 & 2.177 & -4.385 & 4.510 \\
\hline
\end{tabular}

As shown in Table 6, since all the significant value was greater than alpha at 05 level of significance, there was no sufficient evidence to reject the null hypothesis. It can be concluded that there is no significant difference between experimental and control groups' pretest scores in PLST, FSIT, RT, ST and ORFT. Results from the Levene's test also showed that the equality of variances is assumed. Therefore, participants in both groups had similar levels of reading fluency and spelling ability and so were deemed comparable prior to the intervention.

\subsection{The Relative Effect of SSP and SBELC Phonics Training}

To find out if there was a difference between the posttest scores of PLST, FSIT, RT, ST and ORFT assessments of the SSP group and SBELC phonics group, an analysis 
of paired-samples t-test was computed. This was to analyse the mean scores of the pretest and the posttest of the experimental and control groups. The significance level is specified at .05 (alpha, $\alpha=.05$ ). Results are presented in Tables 7 and 8 (for the experimental group), and Tables 9 and 10 (for the control group). To address the hypothesis that the children who undergo the SSP training would demonstrate a better improvement in their reading fluency and spelling ability than the children of SBELC phonics, a comparison was made by looking at the higher Partial Eta Squared value of the two groups. The null hypothesis to be tested (Ho: $\mu 1=\mu 2$ or $\mu 1-\mu 2=0$ ) states that the PLST, FSIT, RT, ST and ORFT mean scores of the pretest are equal to the mean scores of the posttest. Conversely, the alternative hypothesis (H1: $\mu 1 \neq \mu 2$ or $\mu 1-\mu 2 \neq 0)$ states that the PLST, FSIT, RT, ST and ORFT mean scores of the pretest are not equal to the mean scores of the posttest.

Table 7. Paired samples descriptive statistics for the experimental group

\begin{tabular}{cccrrr}
\hline & & N & Mean & Std. Deviation & $\begin{array}{c}\text { Std. Error } \\
\text { Mean }\end{array}$ \\
\hline PLST & Pretest & 16 & 5.688 & 1.195 & .299 \\
& Posttest & 16 & 13.876 & 1.857 & .464 \\
FSIT & Pretest & 16 & 96.625 & 7.013 & 1.753 \\
& Posttest & 16 & 118.750 & 9.842 & 2.461 \\
RT & Pretest & 16 & 10.375 & 2.446 & .612 \\
& Posttest & 16 & 24.875 & 3.096 & .774 \\
ST & Pretest & 16 & 7.500 & 2.129 & .532 \\
& Posttest & 16 & 19.250 & 3.493 & .873 \\
ORFT & Pretest & 16 & 34.500 & 5.808 & 1.452 \\
& Posttest & 16 & 44.375 & 6.956 & 1.739 \\
\hline
\end{tabular}

Table 8. Paired samples t-test for the experimental group

\begin{tabular}{|c|c|c|c|c|c|c|c|c|}
\hline & $\begin{array}{c}\text { Paired } \\
\text { Differences }\end{array}$ & \multirow[b]{2}{*}{ SD } & \multirow[t]{2}{*}{ df } & \multirow{2}{*}{\multicolumn{2}{|c|}{$\begin{array}{l}\text { Sig. (2- } \\
\text { tailed) }\end{array}$}} & \multirow[t]{2}{*}{$\begin{array}{l}\text { Partial } \\
\text { ETA } \\
\text { Squared }\end{array}$} & \multicolumn{2}{|c|}{$\begin{array}{l}95 \% \text { CI of } \\
\text { Difference }\end{array}$} \\
\hline & Mean & & & & & & Lower & Upper \\
\hline PLST (PT-PST) & -8.188 & 1.109 & -29.54 & 15 & .000 & .880 & -8.778 & -7.597 \\
\hline FSIT (PT-PST) & -22.125 & 3.557 & -24.88 & 15 & .000 & .641 & -24.020 & -20.230 \\
\hline RT (PT-PST)) & -14.500 & 1.633 & -35.52 & 15 & .000 & .878 & -15.370 & -13.630 \\
\hline ST ((PT-PST) & -11.750 & 2.266 & -20.74 & 15 & .000 & .815 & -12.957 & -10.543 \\
\hline ORFT (PT-PST) & -9.875 & 2.825 & -13.98 & 15 & .000 & .388 & -11.381 & -8.369 \\
\hline
\end{tabular}

Note. PT - Pretest, PST - Posttest

On average, based on the descriptive statistics shown in Table 7, it seems that the experimental group performed better in the posttest. Since all mean differences are negative (see Table 8), the posttest results are better than the pretest results. The results suggest that there is sufficient evidence to reject the null hypothesis as all the significant value was smaller than alpha at .05 level of significance. Thus, it can be concluded that SSP had a significant effect on the children's reading fluency and spelling ability. 
Table 9. Paired samples descriptive statistics for the control group

\begin{tabular}{cccrrr}
\hline & & N & Mean & Std. Deviation & $\begin{array}{c}\text { Std. Error } \\
\text { Mean }\end{array}$ \\
\hline PLST & Pretest & 16 & 5.750 & 1.390 & .348 \\
& Posttest & 16 & 10.188 & 1.940 & .449 \\
FSIT & Pretest & 16 & 96.938 & 6.550 & 1.637 \\
& Posttest & 16 & 108.563 & 9.252 & 2.313 \\
RT & Pretest & 16 & 10.750 & 2.206 & .552 \\
& Posttest & 16 & 20.313 & 3.005 & .751 \\
ST & Pretest & 16 & 8.125 & 2.306 & .576 \\
& Posttest & 16 & 14.063 & 2.670 & .668 \\
ORFT & Pretest & 16 & 34.438 & 6.491 & 1.623 \\
& Posttest & 16 & 39.938 & 7.316 & 1.829 \\
\hline
\end{tabular}

Table 10. Paired samples t-test for the control group

\begin{tabular}{|c|c|c|c|c|c|c|c|c|}
\hline & \multicolumn{2}{|c|}{$\begin{array}{c}\text { Paired } \\
\text { Differences }\end{array}$} & \multirow[t]{2}{*}{$\mathbf{t}$} & \multirow[t]{2}{*}{ df } & \multirow{2}{*}{$\begin{array}{l}\text { Sig. (2- } \\
\text { tailed) }\end{array}$} & \multirow{2}{*}{$\begin{array}{c}\text { Partial } \\
\text { ETA } \\
\text { Squared }\end{array}$} & \multicolumn{2}{|c|}{$\begin{array}{c}\text { 95\% CI of } \\
\text { Difference } \\
\end{array}$} \\
\hline & Mean & SD & & & & & Lower & Upper \\
\hline PLST (PT-PST) & -4.438 & 1.504 & -11.80 & 15 & .000 & .648 & -5.239 & -3.636 \\
\hline FSIT (PT-PST) & -11.625 & 4.745 & -9.80 & 15 & .000 & .359 & -14.154 & -9.096 \\
\hline RT (PT-PST)) & -9.563 & 2.309 & -16.57 & 15 & .000 & .778 & -10.793 & -8.332 \\
\hline ST ((PT-PST) & -5.938 & 2.462 & -9.65 & 15 & .000 & .602 & -7.250 & -4.625 \\
\hline ORFT (PT-PST) & -5.500 & 1.713 & -12.85 & 15 & .000 & .144 & -6.413 & -4.587 \\
\hline
\end{tabular}

Note. PT - Pretest, PST - Posttest

Overall, based on the descriptive statistics shown in Table 9, participants in the control group appears to perform better in the posttest as compared to the pretest. From the results of the paired samples t-test (Table 10), since all mean differences are negative, the posttest results are better than the pretest results. Since all the significant value was smaller than alpha at .05 level of significance, there was sufficient evidence to reject the null hypothesis. It can be concluded that SBELC phonics had a significant effect on children's reading fluency and spelling ability.

As can be seen, the mean differences between the pretest and posttest for all five assessments show a significant increase in the reading and spelling performances for both experimental (see Table 8) and control (see Table 10) groups at .05 level of significance. However, as seen in the Partial Eta Squared values, the experimental group gained significantly higher in all the five assessments (PLST $=.880, \mathrm{FSIT}=.641, \mathrm{RT}=.878, \mathrm{ST}=.815, \mathrm{ORFT}=.388)$ compared to the control group $(\mathrm{PLST}=.648, \mathrm{FSIT}=.359, \mathrm{RT}=.778, \mathrm{ST}=.602, \mathrm{ORFT}=.144)$. This confirms the hypothesis that children who undergo SSP will attain higher levels of reading fluency and spelling ability than those who receive SBELC phonics.

\subsection{Using Systematic Synthetic Phonics to Accelerate the Acquisition of Early Literacy Skills}

Findings from this study have shown that synthetic phonics, whether systematic (SSP programme) or unsystematic (SBELC phonics), helps children to develop their decoding skills which apply in reading regular or phonetically decodable words. Children from the experimental and control groups recorded significant growth in their decoding ability (assessed through the RT, ST and ORFT). This 
indicates that both approaches were beneficial in building their blending and segmenting skills (two components of synthetic phonics) that had contributed to their improvement in beginning reading. Nonetheless, the experimental group had higher levels of attainment as compared to the control group in productive letter-sound knowledge, phonemic awareness, reading at world level, and spelling, while achieving a similar level in passage reading with the control group. As aforementioned, phonics training only comes after the letter-sound training in the SSP programme. To elaborate, what this essentially means is that the superior performance of the SSP group could be attributed to the following strategies. The reading-supporting strategies were presented in the productive letter-sound training (from grapheme to phoneme), Phase 5 (from written word to oral form) and the after-phase blending session of the phonics training. The spellingsupporting strategies involved the receptive letter-sound training (from phoneme to grapheme), Phases 1 through 5 (from oral form to written word) and the afterphase segmenting activities of the phonics training. The success also lay in the implementation of phases and stages. Children were only allowed to progress to the next phase after completing the current phase, and were only promoted to the next stage after mastering the 5 phases, blending and segmenting sessions in each stage.

To encapsulate, SSP could be the answer for teachers of learners who may be at risk of being left behind and those from a disadvantaged background such as the indigenous groups and/or rural schools (Johnson \& Tweedie, 2010) to gain similar improvements in their learners' early literacy in English language. The empirical evidence gathered in the current study also serves to confirm the success of similar projects using systematic phonics for beginning reading (e.g., Hawkins \& Su, 2013; Zulkifli \& Melor, 2019). However, in addition to reporting the effectiveness of the SSP programme, this article has also thoroughly described the principles and step-by-step procedure of how teachers can carry out the systematic synthetic phonics training in classrooms with their learners. This corresponds with findings from Rabindra et al.'s (2016) study in which teachers are calling for "a specific training session on phonics" as information from courses is often "in a diluted and watered form" (p. 14). This too possibly answers Warid's (2015) calls for more guidance and support for teachers of English Language in indigenous rural schools.

\section{Conclusion}

This study has examined the application of the phonics method in improving young children's early literacy. As discussed previously, reading consists of two distinct components: (i) word-recognition and (ii) comprehension. Phonics instruction supports the development of children's decoding ability that enhances their word-recognition and thus improves their overall early literacy. In this regard, the highly systematic strategies prescribed in SSP can provide a methodological sequence of introducing the synthetic phonics skills and lettersound training. Children in the present study had felt a sense of achievement when they used the SSP strategies and successfully read storybooks independently (Jolly Readers Level 1 and Level 2 had been given for reading after 
the training). This was achieved despite the children's language-disadvantaged background.

Based on the findings, the followings recommendations are offered for further investigations. Firstly, as an improvement, future studies can be repeated for a longer period of time, possibly for the entire school year, and begin phonics training of all the 44 phonemes at the beginning of the school term. Doing so may provide a better idea of whether a complete SSP program helps rural children develop early reading fluency and spelling ability, and if the intervention helps in their overall acquisition of literacy skills in the English language. Another consideration for future research is to increase the sample size for the study, possibly by extending the intervention to other rural schools. Doing so will enable the researcher(s) to collect and analyse more data across more settings and enhance the generalisability of SSP in developing early literacy. Finally, this study focused on word recognition only and has yet to study the effects of SSP on reading comprehension. It is therefore recommended future research to explore this area by incorporating the assessments on complete reading processes; both word recognition and comprehension.

\section{Acknowledgments}

The authors offer their sincerest appreciation to Kuang Ching Hei for her encouragement, and the blind reviewers for their assistance and constructive feedback that have led to the publication of this paper.

\section{References}

Armbruster, B. B., Lehr, F., \& Osborn, J. (2001). Put reading first: The research building blocks for teaching children to read kindergarten through grade 3. Washington, D.C., WA: National Institute for Literacy. Retrieved from http://www.nifl.gov

Beck, I. L., \& Beck, M. E. (2013). Making sense of phonics: The hows and whys (2nd ed.). New York, NY: Guilford Press.

Bowey, J. A. (2011). Need for systematic synthetic phonics teaching within the early reading curriculum. Australian Psychology, 41(2), 79-84. doi:10.1080/00050060600610334

Carpenter, T. P., Fennema, E., Peterson, P. L., Chiang, C. P., \& Loef, M. (1989). Using knowledge of children's mathematics thinking in classroom teaching: An experimental study. American Educational Research Journal, 26(4), 499-531. doi:10.3102/00028312026004499

Chin, M. L. L., Karunakaran, K., \& Yap, J. R. (2019). The role of negotiated interaction in L2 vocabulary acquisition among primary ESL learners. 3L: The Southeast Asian Journal of English Language Studies, 25(2), 1-21. doi:10.17576/3L-2019-2502-01

De Graaff, S., Bosman, A. M. T., Hasselman, F., \& Verhoeven, L. (2009). Benefits of systematic phonics instruction. Scientific Studies of Reading, 13(4), 318-333. doi:10.1080/10888430903001308

Ehri, L. C. (2020). The science of learning to read words: A case for systematic phonics instruction. Reading Research Quarterly, 55(S1), 45-60. doi:10.1002/rrq.334

Eun, H. J. (2012). Oral reading fluency in a second language reading. Reading in a Foreign Language, 24(2), 186-208. Retrieved from http://nflrc.hawaii.edu/rfl 
Griffith, P. L., \& Olson, M. W. (1992). Phonemic awareness helps beginning readers break the code. The Reading Teacher, 45(7), 516-523. Retrieved from https://www.jstor.org/stable/20200912

Harris, T. L., \& Hodges, R. E. (1995). The literacy dictionary: The vocabulary of reading and writing. Newark, DE: International Reading Association. Retrieved from https://eric.ed.gov/?id=ED385820

Hazita, A. (2016). Implementation and challenges of English language education reform in Malaysian primary schools. 3L: The Southeast Asian Journal of English Language Studies. 22(3), 650-678. doi:10.17576/3L-2016-2203-05

Jiang, X., Sawaki, Y., \& Sabatini, J. (2012). Word reading efficiency and oral reading fluency in ESL reading comprehension. Reading Psychology, 33, 323-349. doi:10.1080/02702711.2010.526051

Johns, J., \& Berglund, R. L. (2009). Fluency: Strategies and assessments (3rd ed.). Dubuque, IA: Kendall Hunt Publishing.

Johnson, R. C., \& Tweedie, M. G. (2010). Could phonemic awareness instruction be (part of) the answer for young EFL learners? A report on the early literacy project in Malaysia. TESOL Quarterly, 44(4), 822-829. doi:10.5054/tq.2010.238131

Jolliffe, W., Waugh, D., \& Gill, A. (2019). Teaching systematic synthetic phonics in primary schools (3rd ed.). London, England: Sage Publications.

Malaysia Ministry of Education. (2011). Primary Standard-Based Curriculum Dokumen Standard Kurikulum Sekolah Rendah Bahasa Inggeris SK Tahun Satu \& Dua. Putrajaya, Malaysia: Bahagian Pembangunan Kurikulum.

Malaysia Ministry of Education. (2017). KSSR: Bahasa Inggeris Dokumen Standard Kurikulum dan Pentaksiran Tahun 2. Putrajaya, Malaysia: Bahagian Pembangunan Kurikulum.

McGeown, S. P., Johnston, R. S., \& Medford, E. (2012). Reading instruction affects the cognitive skills supporting early reading development. Learning and Individual Differences, 22(3), 360-364. doi:10.1016/j.lindif.2012.01

Mesmer, H. A. E., \& Griffith, P. L. (2005). Everybody's selling it: But just what is explicit, systematic phonics instruction?. The Reading Teacher, 59(4), 366-376. doi:10.1598/RT.59.4.6

Nadiah Yan, A., Napisah, K., \& Mariyatunnitha, S. (2014). Implementing the teaching of phonics in Malaysian primary schools. Asian Journal of English Language and Pedagogy, 2, 95-111. Retrieved from https://ejournal.upsi.edu.my/index.php/ AJELP/article/view/1103

National Reading Panel. (2000). Teaching children to read: An evidence-based assessment of the scientific research literature on reading and its implications for reading instruction. Reports of the subgroups. Washington, D.C., WA: National Institute of Child Health and Human Development.

Purewal, S. (2008). Synthetic phonics and the literacy development of second language young learners. A literature review of literacy ideologies, policies, and research. (Master's dissertation). University of Leeds, Leeds, England.

Rabindra, D. P., Nooreiny, M., \& Hamidah, Y. (2016). Implementing phonics in Malaysia. International Journal of English Language Teaching and Linguistics, 1(1), 1-18.

Rose, J. (2006). Independent review of the teaching of early reading: Final report. Retrieved from www.standards.dfes.gov.uk/rosereview

Sidhu, G. K., Kaur, S., \& Chi, L. J. (2018). CEFR-aligned school-based assessment in the Malaysian primary ESL classroom. Indonesian Journal of Applied Linguistics, 8, 452463. doi:10.17509/ijal.v8i2.13311

Su, S. C. S., \& Hawkins, J. (2013). THRASS phonics: A case study of Thomas as an emerging reader in English. The English Teacher, 42(1), 52-73. Retrieved from https://journals.melta.org. my/index.php/tet/article/view/231 
Ukrainetz, T. A., Cooney, M. H., Dyer, S. K., Kysar, A. J., \& Harris, T. J. (2000). An investigation into teaching phonemic awareness through shared reading and writing. Early Childhood Research Quarterly, 15(3), 331-355. doi:10.1016/S08852006(00)00070-3

UNICEF. (2008). Education is a human right. Literacy and education in Malaysia: Key actions. Retrieved from http://www. unicef.org/malaysia/index.html

Wang, M., \& Koda, K. (2005). Commonalities and differences in word identification skills among learners of English as a second language. Language Learning, 55, 71-98. doi:10.1111/j.1467-9922.2007.00416.x

Warid, M. (2015). The English language curriculum in Malaysian indigenous primary classrooms: The reality and the ideal. 3L: The Southeast Asian Journal of English Language Studies. 21(3), 1-12. Retrieved from http:// ejournals.ukm.my/31/article/view/8580

Watts, Z., \& Gardner, P. (2012). Is systematic synthetic phonics enough? Examining the benefit of intensive teaching of high frequency words (HFW) in a year one class. Education 3-13: International Journal of Primary, Elementary and Early Years Education, 1-10. doi:10.1080/03004279.2012.710105

Wyse, D., \& Goswami, U. (2008). Synthetic phonics and the teaching of reading. British Educational Research Journal, 34(6), 691-710. doi:10.1080/01411920802268912

Yap, J. R. (2014). Using systematic synthetic phonics as an approach for early literacy. The case of rural indigenous children (Master's thesis). University of Malaya, Kuala Lumpur, Malaysia). Retrieved from http://studentsrepo.um.edu.my/5425/

Zulkifli, A., \& Melor, M. Y. (2019). The effectiveness of using Jolly Phonics blending phonemes to Year 3 English Language classroom. International Journal of Humanities, Philosophy and Language, 2(8), 150-162. doi:10.35631/ijhpl.280011 